\title{
DIREITO A PRESTAÇÃO DE ALIMENTOS NA VELHICE
}

\author{
Daniela Cazarotti Rotta, Ricardo Gabriel de Araújo
}

Universidade do Oeste Paulista - UNOESTE, Presidente Prudente, SP. E-mail: danielacazarotti@gmail.com, ricardoaraujo@unoeste.br.

\section{RESUMO}

O presente artigo tem como objetivo a discussão sobre os direitos dos idosos em receber alimentos, denominação dada pela legislação com o objetivo de suprir as necessidades fundamentais do idoso desamparado.

Sendo um comprometimento primeiramente familiar e na falta desta pelo Estado de prestar assistência material aos idosos, quando os mesmos, não tiver recursos suficientes para ter uma vida digna para a sua subsistência. Estudando seus conceitos, consequências e assegurando de uma forma digna de envelhecimento, pois asseguradas principalmente pela Constituição Federal, como direito fundamental, e agora em legislação especial, a do Estatuto do Idoso, no Código Civil e também e também nas demais leis nacionais e internacionais no que abriga o presente assunto.

A metodologia consta de levantamentos bibliográficos acerca dos principais questionamentos que versam sobre o assunto. Com a presente pesquisa constatou-se que a existência de controversas quando se refere a Alimentos para Idosos, podendo causar grande desafetos no chamado âmbito familiar.

Palavras - Chave: Alimentos para idosos, Abandono, Idosos.

\section{RIGHT TO FOOD SUPPLY IN OLD AGE}

\begin{abstract}
This article aims to discuss the rights of the elderly to receive food, name given by the law in order to meet the basic needs of the destitute elderly.

It is a first family commitment and in the absence of the State to provide material assistance to the elderly, when they do not have enough resources to have a dignified life for their livelihood. Studying their concepts, consequences and ensuring a dignified aging as primarily guaranteed by the Constitution as a fundamental right, and now in special legislation, the Statute of the Elderly, the Civil Code and also and also in other national and international laws in which houses this matter.

The methodology consists of literature surveys about the main questions that deal with the subject. With this research it was found that the existence of controversial when it comes to foods for the elderly, may cause great disaffection in the so called family environment.
\end{abstract}

Keywords: Food for the elderly, Abandonment, Seniors. 


\section{INTRODUÇÃO}

O envelhecimento é um processo inerente a todo ser vivo, desta forma é possível o homem sofrer com as transformações físicas e mentais geradas pelo decorrer dos anos, porém, é fundamental que possam acontecer de uma forma menos dolorosa e mais saudável.

Com o aumento da população idosa, faz-se necessário, uma maior dedicação a este assunto sendo indispensável à apliçção dos preceitos legais destinados ao idoso, é cada vez mais comuns relatos sobre o desrespeito e a negação dos direitos fundamentais a esta faixa etária.

Mostrando a omissão das famílias e do Estado perante os idosos que se encontram em condições vulneráveis de existência. A obrigação alimentar, que é algo imanente a sobrevivência e a uma vida digna.

Enquanto seus filhos e demais parentes vivem em situação muito confortável. Muitos destes idosos tinham situação estável e se despojaram de seus bens em benefício dos filhos esperando por um amparo que nunca chega.

E são estes casos que merecem atenção especial pois a lei prevê que a família é a primeira e principal responsável pelo seu idoso e o Estado só deve atuar quando a família não existe ou é também carente e segundo porque cada vez que um idoso que tem uma família rica faz uso dos parcos recursos públicos isto significa que um idoso carente deixou de ser atendido.

O Artigo 1.696 e 1.697 do Código Civil estabelece que o direito a prestação de alimentos é recíproco entre pais e filhos e na falta dos ascendentes cabe a obrigação dos descendentes, respeitando a ordem de sucessão.

Os alimentos devem ser fixados na proporção das necessidades do idoso e dos recursos da pessoa obrigada.

\section{METODOLOGIA}

O artigo foi embasado em pesquisas bibliográficas, leituras, bem como em leis, resoluções e artigos eletrônicos. Os dados foram examinados com a aplicação do método hipotéticodedutivo, isto é, partindo do geral para o particular e as informações coletadas analisadas e confrontadas de forma dialética.

\section{DISCUSSÃO}

O direito a alimentos das pessoas idosas está previsto, de forma expressa, na Carta Magna de 1988, que, em seu artigo 229, dispõe que: "os pais têm o dever de assistir, criar e educar os filhos menores, e os filhos maiores têm o dever de ajudar e amparar os pais na velhice, carência ou enfermidade."

Inicialmente este direito foi regulamentado pelo código civil de 1916, o qual dispôs sobre a obrigação alimentar recíproca entre pais e filhos (art. 397), prevendo, ainda, que os alimentos deveriam ser fixados na proporção das necessidades do alimentado e das possibilidades do alimentante (art. 400).

De todo modo, em se tratando dos pais que buscavam alimentos dos filhos, a dúvida era saber se haveria um litisconsórcio passivo necessário ou se a integração à lide dos filhos seria facultativa, o que ensejou algumas polemicas e dividiu opiniões.

Dai o código civil de 2002 expressamente ter adotado, com este intuito, um novo regramento:

Art. 1.698 Se o parente, que deve alimentos em primeiro lugar, não estiver em condições de suportar totalmente o encargo, serão chamados a concorrer os de grau imediato; sendo varias as pessoas obrigadas a prestar alimentos, todas devem concorrer na proporção dos respectivos recursos, e, intenda a ação contra uma delas, poderão as demais ser chamadas a integrar a lide. 
Ocorre que um fato novo veio jogar mais lenha na fogueira destas controvérsias: trata-se do inusitado preceito contido no estatuto do idoso, ora transcrito: Com o advento do Estatuto do Idoso (lei 10.741/2003), toda a construção doutrinária e jurisprudencial acerca da proibição da solidariedade alimentar ruiu, pois o artigo 12 do referido diploma legal prevê que "a obrigação alimentar é solidária, podendo o idoso optar entre os prestadores".

Este dispositivo entra em rota de colisão com praticamente toda a doutrina e jurisprudência que sustentam que a obrigação alimentar não é solidaria, mas conjunta e divisível. Ou seja, havendo pluralidade de devedores, cada um responde por uma parte da divida, na medida de suas possibilidades.

Aliás, este o regimento imposto pelo código civil 2002, em seu Art. 1696 o direito à prestação de alimentos é recíproca entre pais e filhos, e extensivo a todos aos ascendentes, recaindo a obrigação nos mais próximos em grau, uns em falta de outros.

Hoje, portanto, pode o idoso ingressar com uma ação de alimentos e exigir de um único parente todo valor indispensável para a manutenção de sua condição social, devendo este, apesar de não ser o único parente obrigado a prestar alimentos, prestá-los de forma integral, podendo, posteriormente, exigir dos demais o rateio do valor pago.

Já os alimentos devidos às pessoas maiores de 60 anos são solidários, podendo um único credor ser demandado para cumprir a prestação alimentar em sua totalidade.

Com efeito, suas regras buscam assegurar direitos fundamentais inerentes à pessoa do idoso e impõe obrigações legais a todos:

Art. 3 É obrigação da família, da comunidade, da sociedade e do poder publico assegurar ao idoso, com absoluta prioridade, a efetivação do direito à vida, à saúde, à alimentação, à educação, à cultura, ao esporte, ao lazer, ao trabalho, à cidadania, à liberdade, à dignidade, ao respeito e à convivência familiar e comunitária.

O Estatuto do Idoso é uma conquista de toda sociedade e não somente dos seus beneficiários mais diretos, ainda que muitos se esqueçam de que durante décadas de vida tais pessoas empregaram toda sua força laboral para a construção da riqueza comum. Alguns, inclusive, não se conscientizam que a velhice é o destino normal da espécie.

O Direito de Família deve sempre estar atento à situação dos idosos. Não para mirá-los com piedade, mas objetivando assegurar-lhes direitos e faculdades condizentes com a fase existencial em que se encontram. Para tanto, o novo estatuto traz avanços notáveis: se as normas por si só não alteram a realidade, ao menos sua existência facilita e assegura as transformações.

O direito aos alimentos é imprescritível por envolver estado de pessoas e dignidade humana. Mesmo que o credor deixe transcrever longo tempo sem exigir os alimentos de seus parentes, poderá exercer sua pretensão a qualquer momento.

Segundo Maria Berenice Dias em seu livro Manual de Direito das Famílias, a palavra idoso pode apresentar uma conotação pejorativa, sendo cercada de certo desprestigio dispondo quase de um conteúdo ofensivo, originando inclusive, uma série de expressões para identificar as pessoas que somente deixaram de ter plena capacidade competitiva na sociedade como: terceira idade, melhor idade, adulto maduro, adulto maior e etc. existindo sempre um questionamento de em qual idade o individuo se torna idoso.[1]

O idoso que não possuir condições e nem família para suprir suas necessidades deverá buscar ajuda junto ao Estado, mas não tolerando situações em que o idoso não possua condições para sua própria subsistência, mas houver família que possa suprir tais necessidades, desta maneira, não deve se deixar aos cuidados de uma entidade publica aquele que possui uma família abastada.

Os pais idosos têm o direito de receber pensão alimentícia dos filhos quando não possuírem meios de manutenção própria ou recursos suficientes para a subsistência. "Alimentos" é utilizado de forma ampla pela lei e compreende tanto o valor necessário para a alimentação em 
si quanto o imprescindível para a manutenção da pessoa de forma geral, vale dizer, recursos para remédios, assistência médica, pagamento de despesas básicas como água, luz, gás, telefone e até cuidadores ou empregados, se o idoso não puder viver sozinho.

O direito a alimentos decorre do princípio da solidariedade familiar e pode ser considerado um direito fundamental por ser essencial para a sobrevivência do indivíduo, salvaguardando sua vida, saúde e dignidade. Dessa forma, "na obrigação alimentar um parente fornece a outro aquilo que lhe é necessário a sua manutenção, assegurando-lhe meios de subsistência, se ele, em virtude de idade avançada (...), estiver impossibilitado de produzir recursos materiais com o próprio esforço"[3].

\section{OS DIREITOS DOS IDOSOS}

De acordo com o art. 1 ㅇ do Estatuto do Idoso (Lei no 10.741/03), idoso é toda pessoa com idade igual ou superior a 60 (sessenta) anos.

Os direitos dos idosos encontram fundamento na Constituição Federal de 1988, Lei no Estatuto do Idoso (Lei no 10.741/03) e no Código Civil de 2002.

A Constituição Federal traz em seu Art. 230:

A família, a sociedade e o Estado têm o dever de amparar as pessoas idosas, assegurando sua participação na comunidade, defendendo sua dignidade e bem-estar e garantindo-Ihes o direito à vida.

$\S 10$ - Os programas de amparo aos idosos serão executados preferencialmente em seus lares.

$\S 2$ - Aos maiores de sessenta e cinco anos é garantida a gratuidade dos transportes coletivos urbanos.

Este dispositivo, se analisado com maior acuidade, dentro da ideia da dignidade da pessoa humana, não se reporta somente à assistência material ou econômica, mas também à afetiva, à psíquica. Se assim não fosse, por qual motivo haveria remissões à participação do idoso na comunidade, com a defesa de sua dignidade, do seu bem-estar, enfim, à salvaguarda do direito a uma vida em toda a sua plenitude?

O Estatuto do Idoso, Lei no $10.741 / 03$, representou um relevante marco para o estudo dos direitos da pessoa idosa. Os direitos fundamentais ali previstos garantiram, com absoluta prioridade, a efetivação dos direito à vida, à saúde, à alimentação, à educação, à cultura, ao esporte, ao lazer, ao trabalho, à cidadania, à liberdade, à dignidade, ao respeito e à convivência familiar e comunitária dos idosos.

O Estatuto do Idoso, por sua vez, em seu art. 12, estabelece que "a obrigação alimentar é solidária, podendo o idoso optar entre os prestadores". Dessa maneira, há um conflito entre o estabelecido no Estatuto do Idoso e o Código Civil.

A respeito disso, Maria Berenice Dias aponta: Apesar de ter origem na solidariedade familiar (1.695), enorme é a dificuldade de considerar que a obrigação é solidária. O fato de estar condicionada à possibilidade de cada prestador decorre da proporcionalidade, o que não muda a natureza da obrigação. O que estabelece o Código Civil é a subsidiariedade da obrigação concorrente (1.696 e 1.697), o que não exclui a solidariedade, tanto é assim que é possível chamar em juízo os demais obrigados (art. 1.698).

A Lei no 10.741/03, atribuiu natureza solidária obrigação de prestar quando idosos, que força da sua natureza especial prevalece sobre as específicas do Código Civil. O Estatuto do Idoso, cumprindo política pública (art. 3으), assegura celeridade no processo, impedindo intervenção de outros eventuais devedores de alimentos. A solidariedade de obrigação alimentar devida ao idoso Ihe garante a opção entre os prestadores (art. 12). Recurso especial não conhecido. (STJ, 3a Turma. REsp 775.565/SP (2005/0138767-9). Mina Nancy Andrighi. j. 26.06.06)[4] 
A obrigação dos filhos perante os pais idosos está alicerçada nos princípios constitucionais do Direito de Família e nos demais diplomas legais acima citados.

Segundo Marco Antonio Vila Boas: Infelizmente precisou que tal dispositivo ficasse assim escrito. É vergonhoso que a obrigação alimentar, mais moral que material, necessitasse ficar registrada na Lei Maior. Este dever é anterior a qualquer lei. É uma obrigação de cunho afetivo e moral. Qualquer filho que tenha caráter e sensibilidade terá que cumprir fielmente este dever de consciência.[5]

Alimentos são prestações para satisfação das necessidades vitais de quem não pode provêlas por si. A expressão designa medidas diversas. Ora significa o que é estritamente necessário à vida de uma pessoa, compreendendo, tão somente, a alimentação, a cura, o vestuário e a habitação, ora abrange outras necessidades, compreendidas as intelectuais e morais, variando conforme a posição social da pessoa necessitada. (GOMES, 1999, p. 427).[7]

\section{CONCLUSÃO}

Neste artigo podemos entender o porquê da necessidade dos alimentos em relação à situação dos idosos para manter sua integridade quando não possuir mais condições de suprir sozinhas suas necessidades básicas de subsistência, como habitação, assistência médica, vestuário.

Direito à vida que é o mais fundamental de todos os direitos garantindo ao seu pretendente uma existência digna.

Um dos principais elementos da família, enquanto geradora de direitos e deveres tutelados por nosso ordenamento civil, é a solidariedade recíproca, é um auxílio mútuo entre pais e filhos e familiares.

Honrar pai e mãe, embora seja um dos mandamentos mais antigos e mais importantes da humanidade, cada vez mais parece ter caído em esquecimento.

Cada vez mais são constantes as notícias de desrespeito, abandono e violência dos filhos para com os pais.

Mas o que é pouco divulgado e quase ninguém sabe é que, em alguns casos, os pais podem pedir pensão aos filhos ou na falta destes para algum parente consanguíneo.

No caso, não tendo o pai recurso para se auto - sustentar, poderá pedir pensão aos filhos.

Os filhos têm a obrigação de amparar seus pais na velhice, seja material, seja imaterialmente, pois os filhos têm com os pais os mesmos deveres que os pais têm com os filhos.

\section{REFERÊNCIAS}

DINIZ, Maria Helena. Curso de Direito Civil Brasileiro. 26. ed. São Paulo: Saraiva, 2011, p. 628, vol. V.

GONÇALVES, Carlos Roberto. Direito Civil Brasileiro: Direito de Família. 6. ed. São Paulo: Saraiva, 2009

DIAS, Maria Berenice, Manual do Direito das Famílias, 6. ed. São Paulo, RT,2010.

VENOSA, Silvio de Salvo. Direito civil: direito de família. 2. ed. São Paulo: Atlas, 2002, v. 6, 378 p.

GONÇALVES, Carlos Roberto. Direito civil brasileiro: teoria geral das obrigações. 2. ed. São Paulo: Saraiva, 2006. Vol. 2.

CAHALI, FRANCISCO JOSÉ, DIREITO DE FAMILIA E O NOVO CODIGO CIVIL, EDITORA DEL REY, 3a EDIÇÃO, COORDENADORES: MARIA BERENICE DIAS E RODRIGO DA CUNHA PEREIRA. 
RODRIGUES, SILVIO, DIREITO CIVIL - VOLUME 2 - PARTE GERAL DAS OBRIGAÇÕES, EDITORA SARAIVA, 26a EDIÇÃO

WALD, AROLDO, O NOVO DIREITO DE FAMILIA, EDITORA SARAIVA, 13a EDIÇÃO

VADE MECUM 2016 - EDITORA SARAIVA, 21a EDIÇÃO

[1] DIAS, Maria Berenice, Manual do Direito das Famílias, 6. ed. São Paulo: RT, 2010. p. 460.

[3]DINIZ, Maria Helena. Curso de direito civil brasileiro: direito de família. 22. ed. São Paulo: Saraiva, 2007. p. 537.

[4]BRASIL. STJ: jurisprudência: pesquisa. Disponível em: <http://www.stj.jus.br/SCON/jurisprudencia/toc.jsp?tipo_visualizacao=null\&processo=775565\&b= ACOR>. Acesso em: 15 jun. 2012.

[5]VILAS BOAS, Marco Antonio. Estatuto do Idoso comentado. Rio de Janeiro: Forense, 2005. p. 31.

[7] GOMES, Orlando. Direito de Família. 11. ed. Rio de Janeiro: Forense, 1999. 427 p. 